\title{
Modelling of fine soils railway embankments behaviour under real cyclic loads
}

\author{
Soufiane GUESSOUS, Nouzha LAMDOUAR \\ Mohammedia School of Engineering (E.M.I) - Mohammed V University in Rabat - Morocco
}

\begin{abstract}
Before the development of regulations, standards and guides for infrastructure building, embankments were generally constructed, by reusing and compacting the excavation materials. Therefore, a large part of existing railway embankments, over the world, is composed of fine compacted soils such as clay or marl. However, the current international trend of the railway undertakings and transport contractors is within the intensification of traffic, and the increase of train's load and speed. Therefore, infrastructure managers are always called upon to evaluate the bearing capacity of existing infrastructures and define the necessary reinforcement solutions. In this perspective, a better awareness and knowledge of the behaviour of fine soils railway embankments is required to define optimal and efficient reinforcement solutions. In that matter, the article will feature the results of finite elements modelling of instrumented railway embankments that were constructed in Morocco in 1920, with marl compacted soil. The model is based on real applied loads and hydraulic conditions monitored for the last three years, which allow to simulate the hydro-mechanical behaviour of the embankment for this period. The article will be also comparing real monitored deformations recorded by the inclinometers equipping the embankments, with the output of the model using different models and adjustments.
\end{abstract}

\section{INTRODUCTION}

In the last years, the tendency of the railway undertaking and managers has become within increasing the traffic in order to satisfy the demands of their clients. Therefore, the railway industry has known a very important evolution in the last century within the load and speed of trains, and the weight of superstructure elements (figure 1):

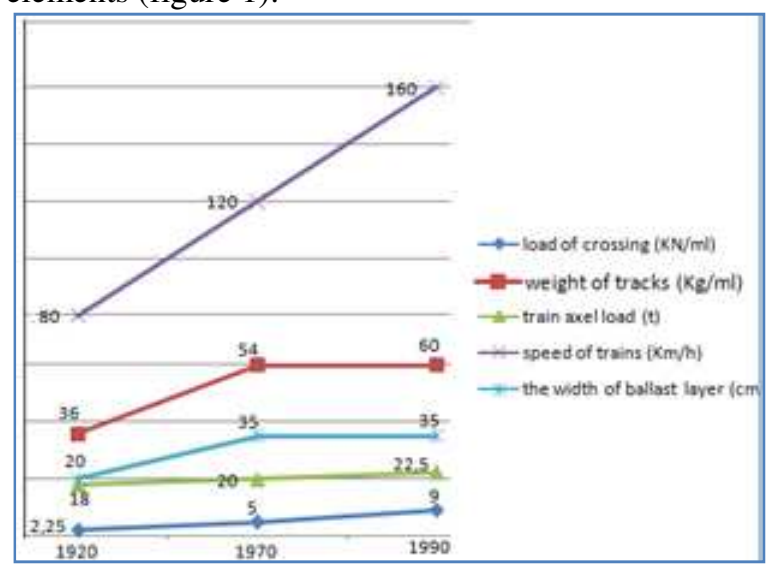

Fig. 1. Evolution of railway loads
However, a large number of existing embankments were constructed in the last $19^{\text {th }}$ and the first of $20^{\text {th }}$ century with clay and marl soils, and submitted millions of hydro mechanical loading cycles, which make the evaluation of their bearing capacity very complicated and difficult.

In that matter, the paper presents the results of a finite elements simulations and modelling of two railway embankments that were constructed in 1920 in morocco using Plaxis 2D version 8.2. These models are based on the geotechnical investigations and the loads monitoring that were conducted in the last three years. The results of the modelling are compared to the deformation recorded for the same period by inclinometers, in order to determine the most convenient materiel model to use in similar modelling and the adjustments to make on the soil characteristics for a better simulation of this type of infrastructures. 


\section{MODEL'S INPUT :}

\subsection{Geometry model:}

The geometry models were based on topographic cross sections in the axes of the inclinometers implemented at the embankments at $\mathrm{Km} 244+520$ of the line Tanger/Fès and $\mathrm{Km} \mathrm{47+960} \mathrm{of} \mathrm{the} \mathrm{line} \mathrm{Fès/Oujda} \mathrm{(figures} \mathrm{2.} \mathrm{\&} \mathrm{3.)}$

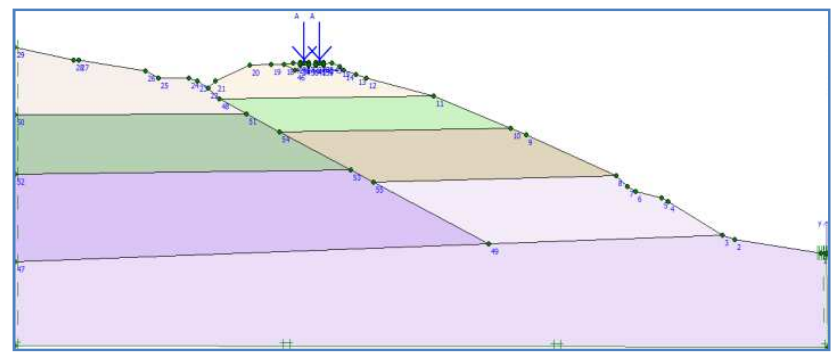

Fig. 2. Geometry model of embankment $1(47+960)$

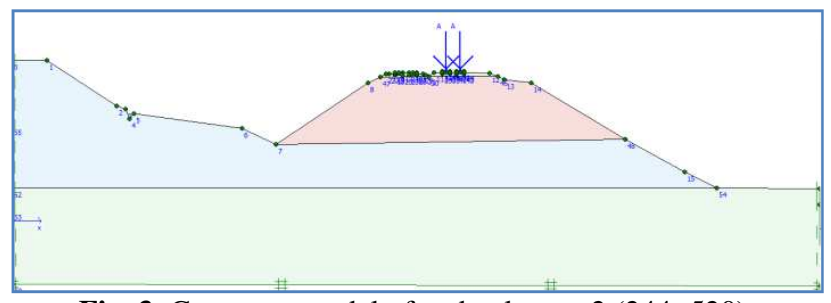

Fig. 3. Geometry model of embankment $2(244+520)$

\subsection{Material setting:}

\subsubsection{Sleepers and ballast characteristics:}

The ballast and the sleepers were modelled by a linear elastic model with the following characteristics according to Sauvage G. (1993) [1], and Profillidis (1983) based on the results of the plate tests conducted at derby (1980) [2]

Table 1. Characteristics of ballast and sleeprs as given by Profillidis (1983) [2]

\begin{tabular}{|c|c|c|c|}
\hline Material & E (MPa) & $\boldsymbol{v}$ & $\boldsymbol{\rho}$ \\
\hline Ballast & 150 & 0,2 & 1,7 \\
\hline $\begin{array}{c}\text { Sleepers (split } \\
\text { concrete) }\end{array}$ & 30000 & 0,25 & 2,4 \\
\hline
\end{tabular}

\subsubsection{Soil models and associated parameters:}

The material model used to characterise the marl soil is the elastoplastic HSM model.

This model is assumed to be isotropic, depending on the plastic shear and volumetric strains. Unlike the MohrCoulomb Model, the stress-strain relationship, due to the primary loading, is a hyperbolic curve in the HSM. The hyperbolic function, as given by Kondner (1963) [3], and later explained by Schanz and al. (1999) [4] and Brinkgreve (2002) [5] is for drained triaxial test:

$\varepsilon 1=\frac{q_{a}}{2 E 50} \frac{q}{q_{a}-q^{\prime}}$

E1: the axial strain,

$\mathrm{q}$ : the deviatoric stress.

A total of 10 input parameters are required in the Hardening Soil Model, although some of them have default values at PLAXIS database. The main parameters are $\gamma$ sat, $\gamma$ unsat, cref, $p$ ref, Eur, Eoed E50 and permeability $(\mathrm{Kx}, \mathrm{Ky})$. These parameters were based on the pressiometer and oedometric tests results. Eur was considered equal to Pressiometric modulus at first and was adjusted owing to the models results. Eoed and E50 were considered approximately as $1 / 3$ of Eur. The following tables summarize the parameters considered for each model:

Table 2. Material HSM parameters for the model of embankment 47+960

\begin{tabular}{|l|c|c|c|c|c|c|c|}
\hline Material & $\begin{array}{c}\gamma \mathbf{s} \\
\text { at }\end{array}$ & $\begin{array}{c}\gamma \mathbf{u n s} \\
\mathbf{a t}\end{array}$ & $\begin{array}{c}\mathbf{C r} \\
\text { ef }\end{array}$ & $\boldsymbol{\varphi r e f ,}$ & $\begin{array}{c}\text { Eur } \\
\mathbf{E} \mathbf{E p}\end{array}$ & Eoed & $\mathbf{E 5 0}$ \\
\hline Clay CF & 20 & 16 & 8 & 20 & 4500 & 1500 & 1500 \\
\hline $\begin{array}{l}\text { Clay } \\
\text { CF2 }\end{array}$ & 20 & 16 & 10 & 24 & 8000 & 2700 & 2700 \\
\hline $\begin{array}{l}\text { CLAY } \\
\text { CF 3 }\end{array}$ & 20 & 18 & 15 & 28 & $\begin{array}{c}1800 \\
0\end{array}$ & 6000 & 6000 \\
\hline $\begin{array}{l}\text { Clay } \\
\text { remblai }\end{array}$ & 18 & 16 & 5 & 22 & $\begin{array}{c}1300 \\
0\end{array}$ & 4300 & 4300 \\
\hline $\begin{array}{l}\text { Clay } \\
\text { subs }\end{array}$ & 18 & 16 & 15 & 26 & $\begin{array}{c}5000 \\
0\end{array}$ & 17000 & $\begin{array}{c}1700 \\
0\end{array}$ \\
\hline Clay TN & 17 & 15 & 5 & 20 & 3600 & 1200 & 1200 \\
\hline $\begin{array}{l}\text { Clay } \\
\text { TN2 }\end{array}$ & 20 & 18 & 5 & 20 & 8000 & 2600 & 2600 \\
\hline $\begin{array}{l}\text { Clay } \\
\text { TN3 }\end{array}$ & 20 & 18 & 15 & 24 & $\begin{array}{c}1300 \\
0\end{array}$ & 4300 & 4300 \\
\hline
\end{tabular}

Table 3. Material HSM parameters for the model of embankment $244+520$

\begin{tabular}{|l|c|c|c|c|c|c|c|}
\hline Material & $\gamma$ sat & $\gamma$ unsat & Cref & pref, & Eur=Ep & Eoed & E50 \\
\hline Remblai & 20 & 18 & 15 & 24 & 10000 & 3000 & 3000 \\
\hline Clay 2 & 20 & 17 & 8 & 22 & 6000 & 2000 & 2000 \\
\hline Clay 3 & 21 & 18 & 15 & 28 & 35000 & 11000 & 11000 \\
\hline
\end{tabular}

\section{METHOD OF ANALYSIS :}

\subsection{Loading :}

Real applied railway loads depend on various factors such as the axel static load, the infinitesimal ondulation of rails, track geometry defaults, ovalisation of wheels, wheel/ rail interface...

Many researches were conducted to determine the relationship between Axle load and track deflection, such as the research of Jaco Vorster \& Hannes Gräbe 
(2010) [6] who used a particle image velocimetry instruments to determine the relationship between Axle load and track deflection, and formulated a logarithmic shape relationship for axel load under $28 \mathrm{t}$ :

$\mathbf{d}=0,50 \ln (\mathrm{F})-0,29$

\section{F: Axel Load, d: Track deflection}

However, the best way to evaluate the axel real applied load is to use instruments and implement loads captors.

Therefore, an in order to reach the precision aimed in the models, the railway real applied loads were recorded for the last two years, by a load monitoring stations that were installed under the tracks near the embankments. This system is based on the measuring of track deflection during the passage of the train's axels.

The monitoring system is composed of twelve fibre optical sensors per track that communicate the measurements to a treatment station.

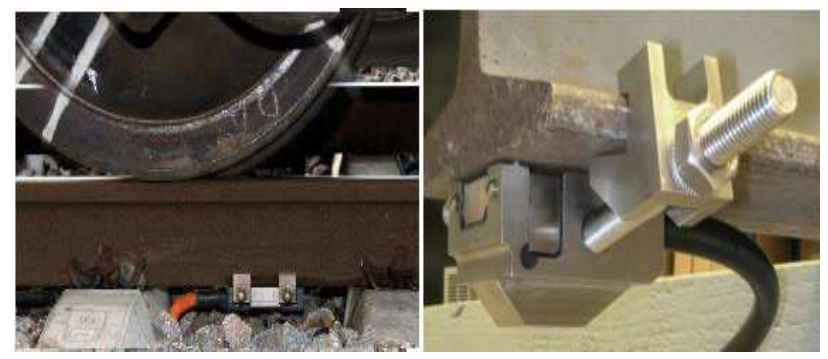

Fig. 4 Optical bending sensors installed under the track

The recorded loads were introduced in the Plaxis models in a shape of different phases of unloading and reloading using the staged construction box.

\subsection{Water conditions:}

In order to define the hydraulic factor and integrate its impact on the soil's deformation, water conditions were defined and adapted according to the rainfall and precipitations recorded in the last two years.

To do so, we used the relationship between rainfall and groundwater level described below.

Under the assumption that the rainfall and groundwater level are proportional and the water stored in the soil is gradually accumulated (figure 5), the expression after $\mathrm{N}$ times of rainfall is given by Conte and Troncone (2016) [7] as :

$h(x, t)=\sum_{j=1}^{N} \frac{h_{r j}}{n\left(1-S_{r}\right)} \exp \left[-k_{T} i \cos \theta\left(t-t_{0 j}\right)\right]$

Where :

- $\theta$ : the angle between infinite slope and horizontal line
- $\mathrm{h}(\mathrm{x}, \mathrm{t})$ : the change in groundwater level in the vertical direction is due to rainfall infiltration

- $\mathrm{Kt}=\mathrm{K} / \mathrm{b}$ : with $\mathrm{K}$ is the permeability of the layer and $\mathrm{b}$ is its width

- hrj is the volume of water in the slope (unit area) due to the rainfall infiltration in jth time

- Sr : saturation degree of the soil

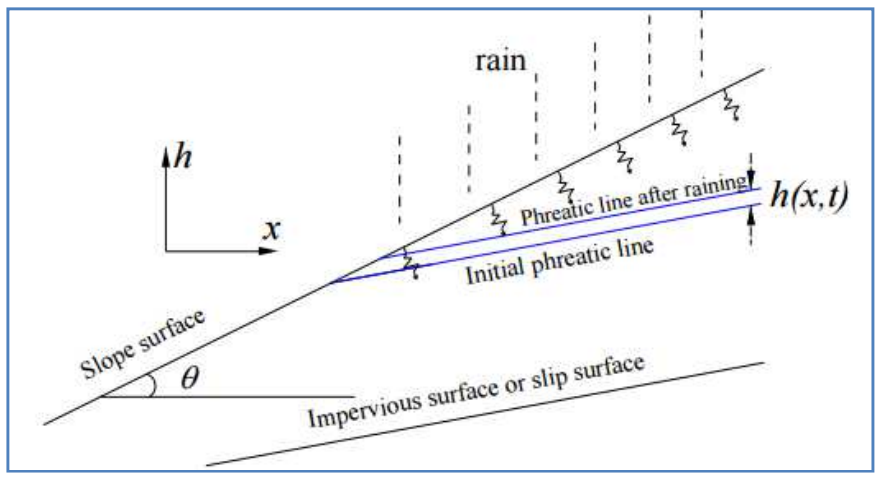

Fig.5 Slope model with an indication of the steady-state groundwater level change owing to rain infiltration $\mathrm{h}(\mathrm{x}, \mathrm{t})$, and the slip surface (modified from Conte Troncone 2016) [7]

Based on these formulations and results, the phreatic level was calculated and changed in the models owing to the rainfall monthly average.

\subsection{Output analysis:}

After operating the calculations, the horizontal displacement curve was extracted at a $1,5 \mathrm{~m}$ depth point from the crest of the slopes in the axis of the implemented inclinometers.

This point was chosen as a reference, because the topper section gives the most significant response to the unloading and reloading cycles and the water conditions fluctuations. Also, the depth of 1,5 $\mathrm{m}$ was chosen in order to avoid the impact of soil's erosion

The horizontal displacement curve was analysed from two perspectives:

$>$ Comparing the results of the models with the real monitored displacements (inclinometers).

$>$ Evaluating the impact of cyclic variable loads and water conditions fluctuation of the embankment's deformation.

\section{RESULTS AND DISCUSSIONS :}

\subsection{Comparison of the models results with the inclinometers monitored displacements}

In order to monitor the real soil displacements, inclinometers were installed at the crests of the embankments with a depth of 30 meters. 
The measurements of these instruments for the last two years were extracted and allowed to establish the curve of mensal displacements evolution:

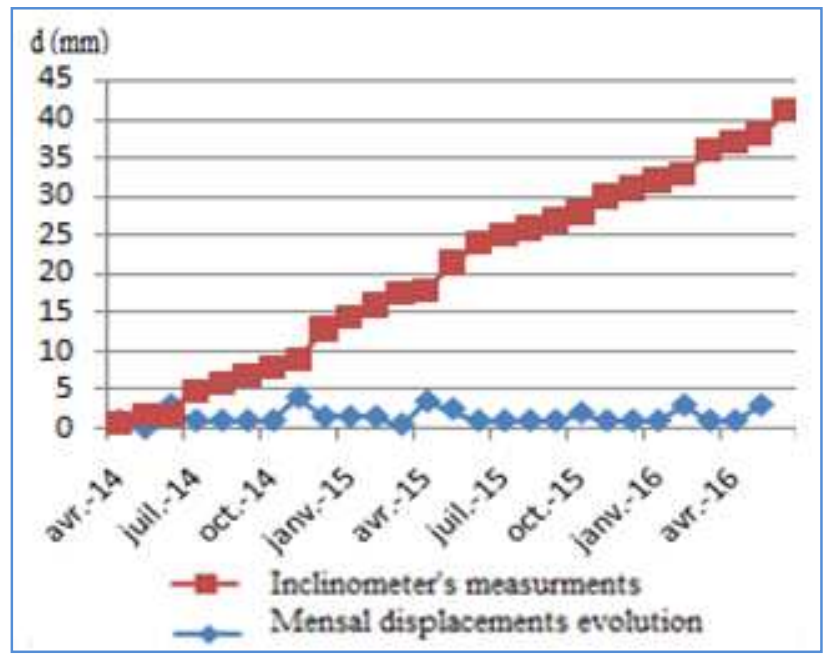

Fig. 6 Inclinometer measurements and mensal displacements evolution for embankment 1

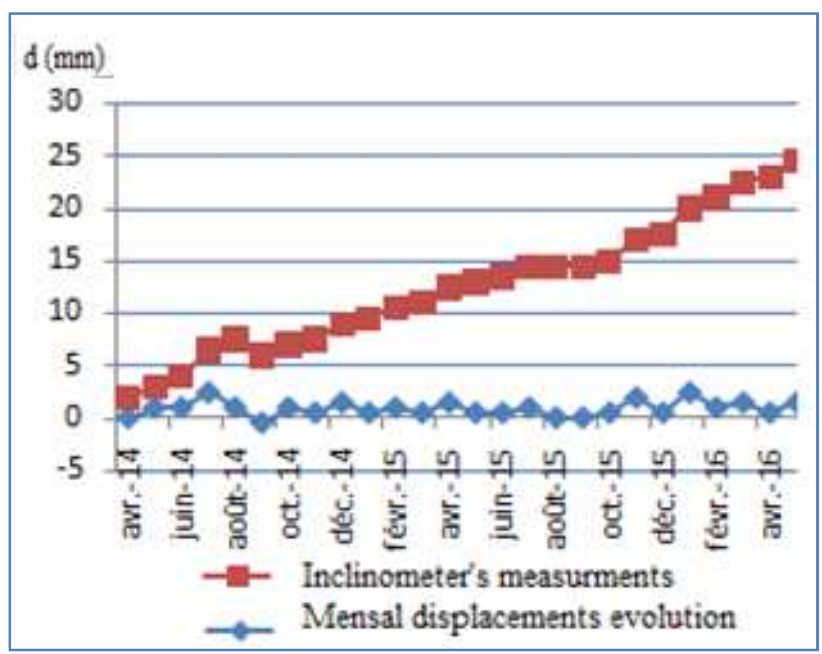

Fig. 7 Inclinometer measurements and mensal displacements evolution for embankment 2

At first,, the unloading reloading stiffness Eur was considered equal to pressiometric modulus in order to have a reference model. Afterwards, the stiffness was modified several times in order to reach and define the optimal Eur/Ep ratio that allows having coherent and similar results with the real measured horizontal displacements. The intervalle considered for the variation of Eur is : ( Ep, 2,5 Ep). This interval is based on experiments conducted by Gomes Correia, Armando and Michel Apageo, in 2004 [8] (figure 8).

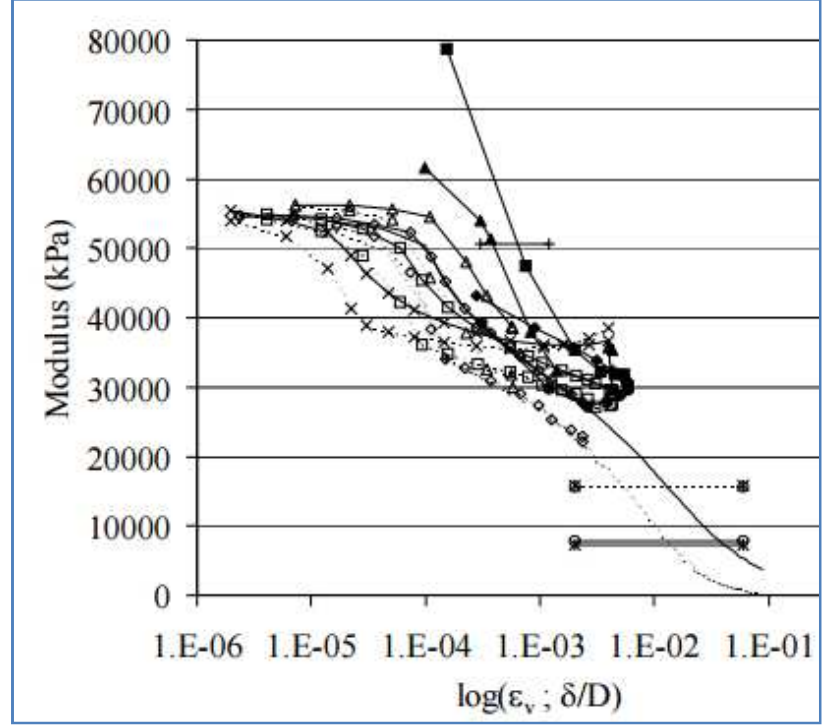

Fig.8 Moduli as a function of strain level for various numerical simulations and test analysis (Gomes Correia, Armando and Michel Apageo, 2004)

The different calculated models showed a convergence between the displacement curve and the measurements of inclinometers for a Eur=1,5 Ep (fig.8).

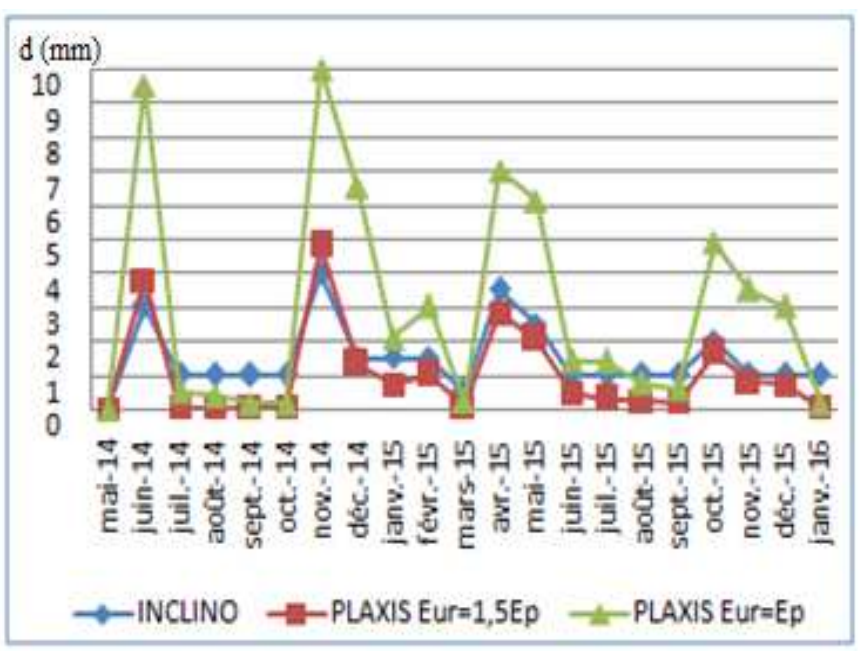

Fig. 9 Inclinometer measurements compared to horizontal displacement calculated with Eur= Ep and Eur=1,5Ep for embankment 1

The same ratio was used in the model of the second embankment and showed a very finite convergence between the measurements and the displacement curve (Fig 9) : 


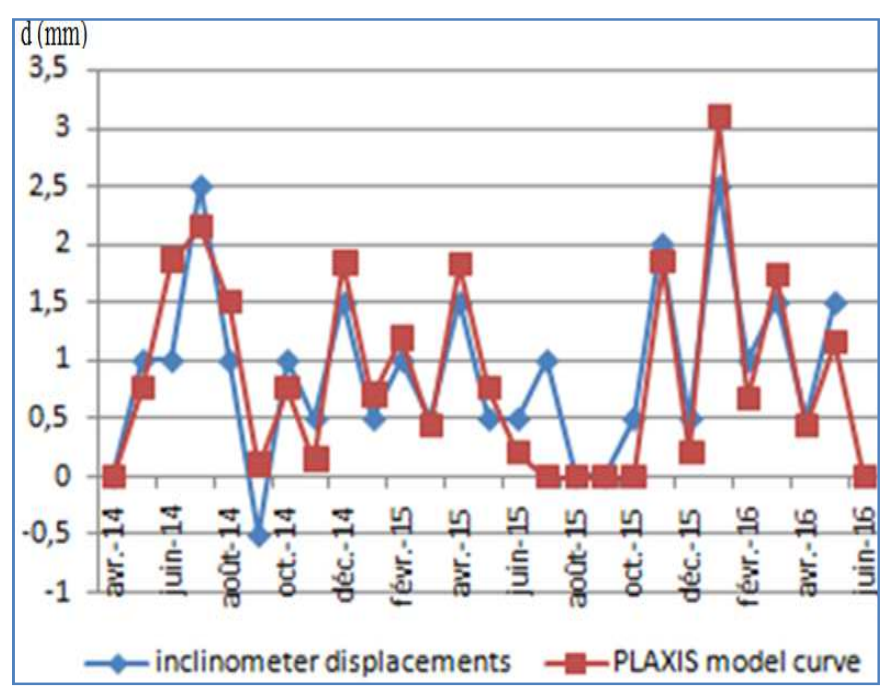

Fig. 10 Inclinometer measurements compared to horizontal displacement calculated with Eur $=1,5 \mathrm{Ep}$ for embankment 2

\subsection{Impact of variable cyclic loads and water conditions:}

The analysis of displacement curves extracted from the models showed that the deformation increases significantly with the groundwater level and the rainfall volume increase. While its much less sensitive to the load increase in the real conditions of railway load fluctuation proportions. Figures 11 and 12 show that after every period of rainfall we have an average displacement of 2-3 $\mathrm{mm} / \mathrm{month}$ within the embankments:

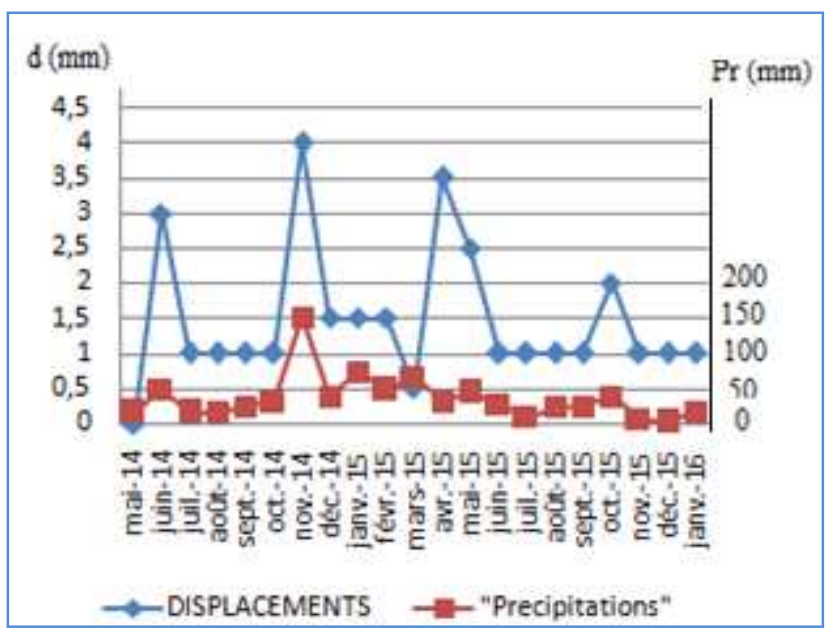

Fig. 11 Mensal displacements and precipitations (embankment 1)

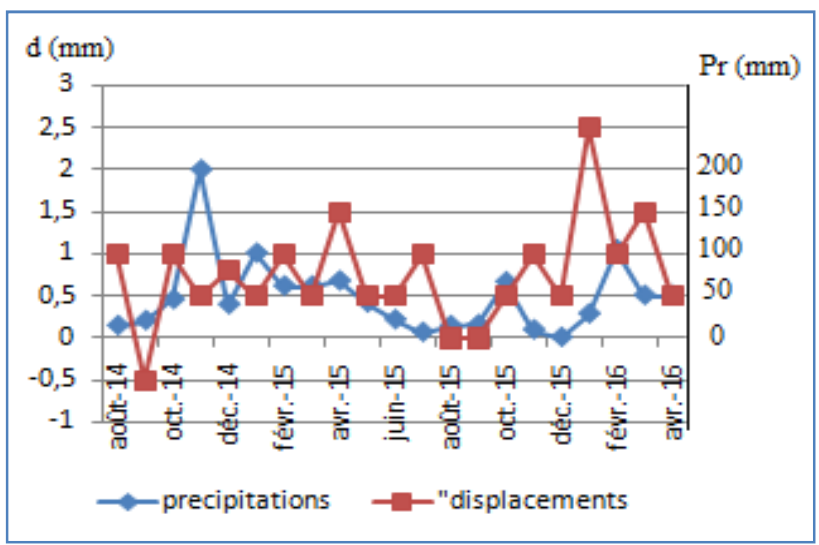

Fig. 12 Mensal displacements and precipitations (embankment 2)

On the other hand, the figure 13 shows that the increase of load impacted the displacements only in two cases where the raise of the load was 7 to $10 \%$.

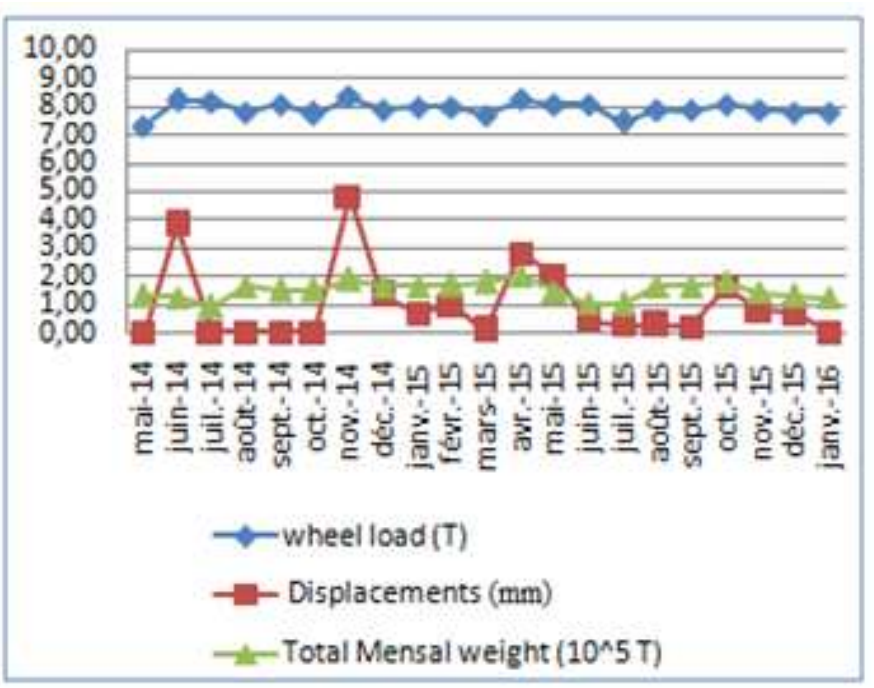

Fig. 13 Evolution of displacements owing the load and total mensal weight.

\section{CONCLUSIONS}

The following conclusions can be drawn from the finite model study and the instrumentation approach described in the article:

- The HSM is a very convenient model for simulating the behaviour of fine soil's railway embankments with a history of cyclic loading and hydraulic fluctuations. In which case, The unloading reloading stiffness can be considered as $3 / 2$ of the Menard pressiometer Modulus for a precise approached results. 
- The irreversible deformation of soft soils embankments depends mainly of the groundwater level and the rainfall volume, and can evaluate by relatively high values ( 2 to $3 \mathrm{~mm}$ per month). While the influence of the load punctual increase is much less significant in the proportions of train load fluctuation ( less than $1 \mathrm{~mm}$ ).

\section{REFERENCES:}

1. Sauvage, G., 1993. Railway track vertical static behaviour, INRETS/LTN.

2. Profillidis, V., 1983. La voie ferrée et sa fondation - Modélisation mathématique. Thèse de doctorat, Ecole Nationale des Ponts et Chaussées.

3. Kondner, R.L., 1963. Hyperbolic stress-strain response cohesive soils. Journal of Soil Mechanics and Foundations Division, ASCE 89, 115-143.

4. Schanz, T., Vermeer, P.A., Bonnier, P.G., 1999. The hardening soil model: formulation and verification, Beyond 2000 in Computational Geotechnics. Balkema, Rotterdam. (1999)

5. Brinkgreve,R.B.J.,.PLAXIS Finite Element Code for Soil and Rock Analysis-version 8.Balkema,Rotterdam. (2002)

6. Hannes Gräbe, Jaco Vorster, Axle load and track deflection on a heavy haul line (2010)

7. Enrico Conte, Antonello Troncone, Antonion DONATO, A simple approach for evaluating slope movements induced by groundwater variations(2016)

8. Gomes Correia, António Universidade do Minho, Portugal. Antão, Armando Universidade Nova de Lisboa, Portugal Gambin, Michel Apageo, France Using a non linear constitutive law to compare Menard PMT and PLT E-moduli (2004) 